\title{
Bibliometric Analysis on Research Trend of Accidental Falls in Older Adults by Using Citespace-Focused on Web of Science Core Collection (2010-2020)
}

\author{
Boyuan Chen ${ }^{1,2}$ and Sohee Shin ${ }^{2, *}$ \\ 1 School of Physical Education (Main Campus), Zhengzhou University, Zhengzhou 450001, China; \\ cby@haust.edu.cn \\ 2 School of Sport and Exercise Science, University of Ulsan, 93 Daehak-ro, Nam-gu, Ulsan 44610, Korea \\ * Correspondence: soheeshin@ulsan.ac.kr
}

Citation: Chen, B.; Shin, S. Bibliometric Analysis on Research Trend of Accidental Falls in Older Adults by Using Citespace-Focused on Web of Science Core Collection (2010-2020). Int. J. Environ. Res. Public Health 2021, 18, 1663. https:// doi.org/10.3390/ijerph18041663

Academic Editors: Francisco José Tarazona Santabalbina, Sebastià Josep Santaeugènia Gonzàlez, José Augusto García Navarro and José Viña

Received: 23 December 2020

Accepted: 5 February 2021

Published: 9 February 2021

Publisher's Note: MDPI stays neutral with regard to jurisdictional claims in published maps and institutional affiliations.

Copyright: (c) 2021 by the authors. Licensee MDPI, Basel, Switzerland. This article is an open access article distributed under the terms and conditions of the Creative Commons Attribution (CC BY) license (https:// creativecommons.org/licenses/by/ $4.0 /)$.

\begin{abstract}
The present study aimed to identify the trends in research on accidental falls in older adults over the last decade. The MeSH (Medical Subject Headings) and entry terms were applied in the Web of Science Core Collection. Relevant studies in English within articles or reviews on falls in older adults were included from 2010 to 2020. Moreover, CiteSpace 5.6.R5 (64-bit) was adopted for analysis with scientific measurements and visualization. Cooper Cyrus, Stephen R Lord, Minoru Yamada, Catherine Sherrington, and others have critically impacted the study of falls in older adults. Osteoporosis, dementia, sarcopenia, hypertension, osteosarcopenia, traumatic brain injury, frailty, depression, and fear of falling would be significantly correlated with falls in older adults. Multiple types of exercise can provide effective improvements in executive cognitive performance, gait performance, quality of life, and can also lower the rates of falls and fall-related fractures. Fall detection, hospitalization, classification, symptom, gender, and cost are the current research focus and development direction in research on falls in older adults. The prevention of falls in older adults is one of the most important public health issues in today's aging society. Although lots of effects and research advancements had been taken, fall prevention still is uncharted territory for too many older adults. Service improvements can exploit the mentioned findings to formulate policies, and design and implement exercise programs for fall prevention.
\end{abstract}

Keywords: older adults; accidental falls; research hotspot; CiteSpace; knowledge domain visualization

\section{Introduction}

With aging, inactivity can lead to adverse and deep consequences, including health, economic, environmental, and social effects [1]. Many people are subject to multiple chronic diseases and drugs in their daily lives [2], which overall elevate the risk of falls for older adults. The annual incidence of falls for people aged over 65 is $30 \%-40 \%$, and the incidence of falls for people aged over 80 is as high as 50\% [3,4], which causes premature mortality, loss of independence, placement in assisted-living facilities, and death. A classification of fall risk factors has been proposed according to extrinsic and intrinsic factors. The extrinsic factors are related to surrounding space or environment-related, taking up to $30 \%-50 \%$ in most series [5], (e.g., tripping, slipping, walking on uneven surfaces, and inadequate illumination). The intrinsic or individual-related causes include advanced age, gait and balance impairment, concomitant chronic conditions (e.g., cardiovascular diseases, and sensory impairment), cognitive deficits, disorders of the central nervous system, severe osteoporosis with spontaneous fracture, and acute illness, drug side-effects, alcohol intake, anemia, hypothyroidism, unstable joints, and foot problems [6].

Falling always causes severe injuries, which is one of the costliest health conditions among older adults, imposing a heavy burden on the health care system [7]. An evidencebased fall prevention program can not only significantly reduce the incidence of fall-related 
injuries and medical costs but also improve the quality of life of older adults. As revealed from high-certainty evidence, exercise can prevent falls [8], which could reduce the rate of falls by $23 \%$ and down-regulate the number of people that experience one or more falls by $15 \%$ in community-dwelling older adults [9]. Furthermore, exercise-based interventions as a cost-effective treatment to prevent falls can benefit older adults substantially by improving their health, independence, and quality of life. Accordingly, regular screening for fall risk and care, and interventions, should be implemented in older adults.

Falls are usually multifactorial, effective prevention strategies are essential to reduce the public health burden on the increasing number of falls and fall-related mortality. Some countries recommend annual instability screening in people aged 65 or over, the geriatric specialists for coping with falls and other geriatric syndromes are increasingly demanded. To this end, it is necessary to conduct a comprehensive summary of the research about accidental falls in older adults over the last decade. An evidence-based fall prevention program can not only significantly reduce the incidence of fall-related injuries and medical costs, but also enhance the public's awareness, and improve the quality of life of older adults. Therefore, articles or reviews in English were downloaded from the Web of Science Core Collection from 2010 to 2020, and Citespace 5.6.R5 (64-bit) (Chaomei Chen, Philadelphia, PA, USA) was used for visualization and interpretation to identify the status and focus of studies regarding falls in older adults, presenting the development direction for following falls studies in older adults.

\section{Method}

\subsection{Data Selected}

The input data of this study was found using a combination of the research results from the multiple topic search queries into the Web of Science Core Collection. This study employed the MeSH and entry terms singularly or in combination (34,899, see Appendix A). First, we ensured that the data being used was from 2010 to 2020.

The second placed stress on older adults and falls. One of the topic terms included "accidental fall*", fall*, "fall*, accidental", "fall and slip", "slip and fall". This query produced 171,659 records as Set \#6. Besides, another topic term consists of aged, elderly, this query led to 1,705,687 records as Set \#9. At last, we combined Set \#6 and Set \#9 together and got the final dataset, Set \#10, containing 34,899 records.

Similar queries \#1-\#10 were employed here to retrieve bibliographic records on the common data sources for science mapping, including PubMed (14,025, see Appendix B), Embase (15,588, see Appendix C), Scopus (33,624, see Appendix D). Books, documents, and research grants, or other types of data sources may be required to be considered. However, this review is only limited to the records of types of articles or reviews in English in the Web of Science Core Collection.

All bibliographic information was downloaded and saved as plain text files for subsequent data processing and analysis. Subsequently, the data were imported into the Citespace and the duplicate data were deleted to prepare for the next step of visualization.

\subsection{Data Analysis Method}

Citespace refers to an information visualization tool extensively applied in the field of knowledge graphs [10]. Visualization tools were adopted to display and analyze the knowledge context of a certain domain, and the development process and structural relationship in this domain were suggested. Therefore, this review adopted CiteSpace 5.6.R5 (64-bit) to achieve visualization to gain insights into this field of accidental falls in older adults and discover the research frontier and knowledge base of the field in considerable data.

Notably, when the clustering function was started, the Modularity Q and the Mean Silhouette scores critically impacted visualization, representing an overall structural characteristic of the network. Overall, $Q>0.3$ displayed an overall significant structure. If $S>0.5$ or higher, the cluster was usually considered to be reasonable [11]. 


\section{Result}

\subsection{Analysis Results and Visualization}

3.1.1. Basic Statistical Analysis

The number of papers published regarding falls in older adults was elevated from 2127 in 2010 to 4244 in 2020 (Figure 1). It is suggested that falls in older adults are attracting rising attention from researchers.

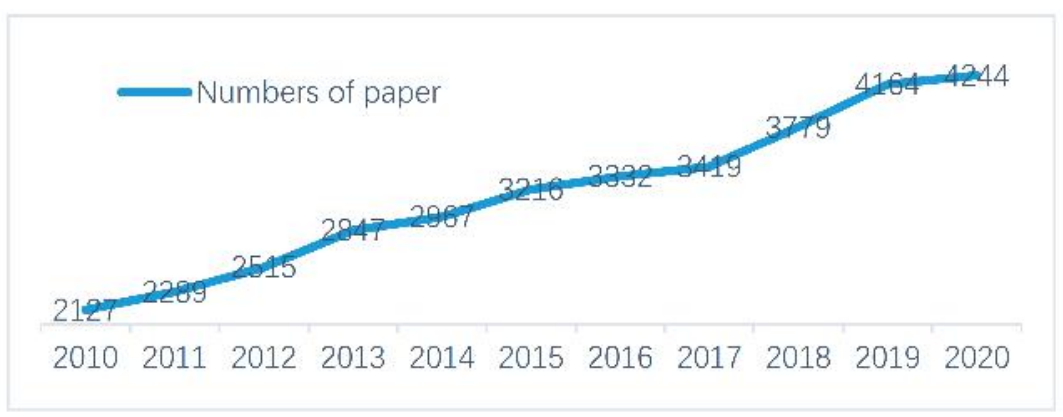

Figure 1. Papers regarding accidental falls in older adults (2010-2020).

\subsubsection{Distribution of Journal Papers}

Table 1 lists the top 10 journals that published the largest number of papers regarding falls in older adults from 2010 to 2020. PLoS One published about 609 papers, ranking the first. Overall, the specific subject scope comprises Geriatrics Gerontology, Medical General Internal, Public Environmental Occupational Health, Gerontology, Rehabilitation, Orthopedics, Clinical Neurology, Surgery, Neurosciences, Sport Sciences, and so on. In the listed top 10 journals, the highest impact factor is Age and Ageing, nearly 4.902.

Table 1. Top 10 journal published analysis (2010-2020).

\begin{tabular}{cccccc}
\hline No. & Journal Title & IF & Amount & Country & Research Area \\
\hline 1 & PLoS One & 2.740 & 609 & USA & Science \& Technology-Other Topics (Q2) \\
\hline 2 & Gait \& Posture & 2.349 & 425 & Ireland & $\begin{array}{c}\text { Neuroscience \& Neurology (Q3) } \\
\text { Orthopedics (Q2) } \\
\text { Sport Sciences (Q2) }\end{array}$ \\
\hline 3 & BMC Geriatrics & 3.077 & 366 & England & Geriatrics \& Gerontology (Q2) \\
\hline 4 & Journal of the American Geriatrics Society & 4.180 & 321 & USA & Geriatrics \& Gerontology (Q1) \\
\hline 5 & Archives of Gerontology and Geriatrics & 2.128 & 272 & Ireland & Geriatrics \& Gerontology (Q3) \\
\hline 6 & Osteoporosis International & 3.864 & 271 & England & Endocrinology \& Metabolism (Q2) \\
\hline 7 & Aging Clinical and Experimental Research & 2.697 & 264 & Italy & Geriatrics \& Gerontology (Q3) \\
\hline 8 & BMJ Open & 2.496 & 219 & England & General \& Internal Medicine (Q2) \\
\hline 10 & Journal of the American Medical & 4.367 & 197 & USA & Geriatrics \& Gerontology (Q1) \\
\hline
\end{tabular}

\subsubsection{Co-Institution Analysis}

We ran CiteSpace, generating a network as usual: 2010-2020, Slice length: 1 year; Node Select the node type: Institution, Top $N=20$, choice Pathfinder and Pruning the merged network. Other parameters were the default settings. Also, the Co-institutions knowledge mapping was generated, in which $\mathrm{N}=60, \mathrm{E}=67$ (density was 0.0379).

Figure 2 indicates that the main research strengths were in universities. The University of Sydney has published the most papers and has conducted strong scientific research in the study on falls in older adults. Furthermore, the greatest number of bursts in the study was Harvard Medical School, reaching 59.04. The University of Oxford was the institution 
with the strongest centrality, reaching 8 . The highest-ranked by Sigma was the University of Pittsburgh.

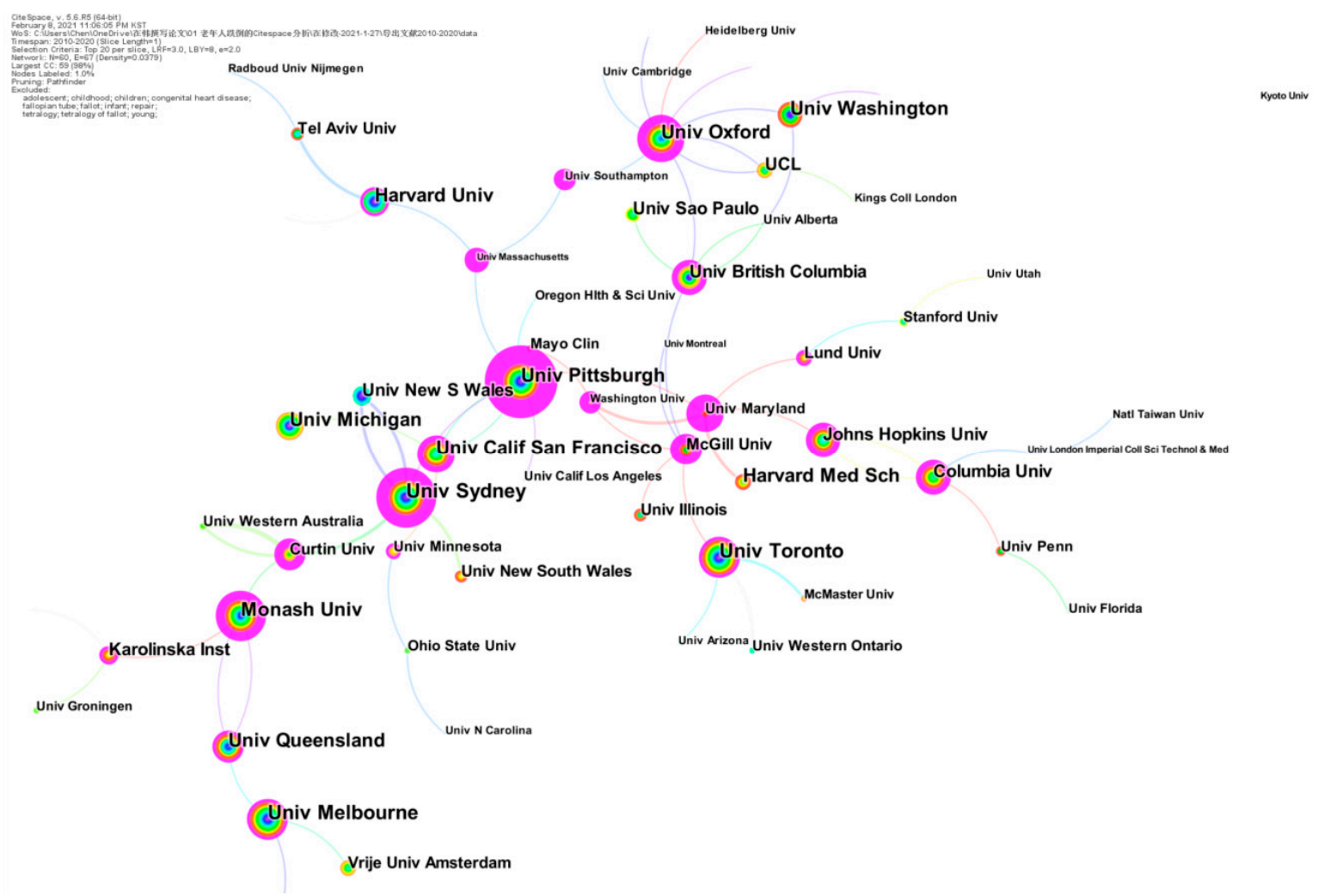

Figure 2. Co-institutions' network (2010-2020). The color of the circle represents when the article was published. The larger the node diameter, the more papers institutions have published. The thicker the line between the nodes, the closer the two institutions work together.

\subsubsection{Co-Author Analysis}

By analyzing the author, the cooperative relationship with others could be investigated. We ran CiteSpace, generating a network as usual: 2010-2020, Slice length: 1 year; Node Select the node type: Author, Top N = 20, and choice Pathfinder and Pruning the merged network, other parameter settings were likely to institutions. This study found knowledge mapping of the co-author with $\mathrm{N}=186, \mathrm{E}=186$ (a density of 0.0108) (Figure 3).

Table 2 shows that Stephen R. Lord ranked first in the number of citations, with 175 citations. The most obvious Burst referred to the Minoru Yamada, reaching 12.13. The strongest centripetal force was Cooper Cyrus, displaying a centripetal force of 8 . The highest Sigma $\left(\sum\right)$ was Catherine Sherrington, and the Sigma was 0.32 .

Table 2. Author rank in different conditions.

\begin{tabular}{|c|c|c|c|c|}
\hline No. & Co-Authorship Papers & Burst & Centrality & Sigma \\
\hline 1 & Stephen R Lord & Minoru Yamada & Cooper Cyrus & $\begin{array}{l}\text { Catherine } \\
\text { Sherrington }\end{array}$ \\
\hline 2 & Kim Delbaere & Koutatsu Nagai & Mirjam Pijnappels & Clemens Becker \\
\hline 3 & Catherine Sherrington & Kazuki Uemura & Teresa Liu-Ambrose & Jacqueline C T Close \\
\hline 4 & Keith D Hill & Anne-Marie Hill & Keith D Hill & Jorunn L Helbostad \\
\hline 5 & Jacqueline CT Close & Noriaki Ichihashi & Jeffrey M Hausdorff & Lindy Clemson \\
\hline
\end{tabular}

Centrality represents the degree of nodes that are part of the path that connects any pair of nodes in the network. Burst refers to the specific time during which a sudden change in frequency occurs. Sigma measures a combination of structural and temporal characteristics of nodes. 


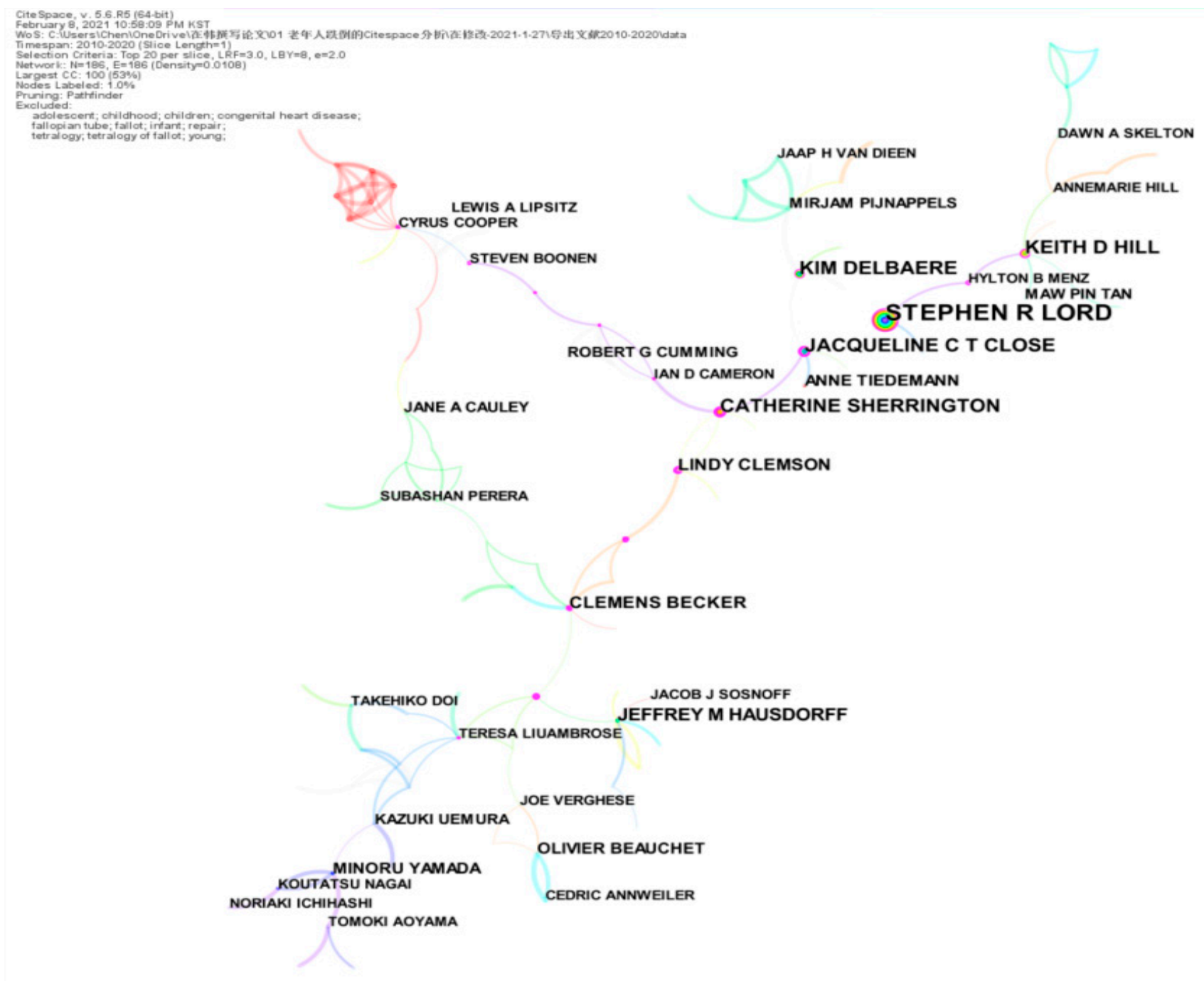

Figure 3. Co-authorship network (2010-2020). The color of the line represents the time the co-authors worked together. The larger the node diameter, the more papers the author has collaborated to publish. The thicker the line between the nodes, the closer the cooperation between the two authors.

The Web of Science was used (Table 3), and Cooper Cyrus's H-index was 144. Professor Cyrus leads an internationally competitive program of research into the epidemiology of musculoskeletal disorders, most notably osteoporosis. Stephen R Lord has published over 600 papers in the areas of balance, gait, falls in older people, and is acknowledged as a leading international researcher in his field. His research primarily focuses on two themes: the identification of physiological risk factors for falls and the development and evaluation of fall prevention strategies. Minoru Yamada's H-index was 28; cited 2501 times. Also, his research follows three main themes: the epidemiological study on sarcopenia and frailty; the effect of a care prevention program on healthy life expectancy; and the effect of physical activity on health outcomes in older adults. Catherine Sherrington's H-index reached 52; cited 11,623 times. Currently, she is leading the Physical Activity, Ageing, and Disability Research Stream within the Institute, and is focused on health, aging falls, and rehabilitation. 
Table 3. Researchers' academic information.

\begin{tabular}{cccl}
\hline Researcher & H-Index & Sum of Cited & \multicolumn{1}{c}{ Research Areas } \\
\hline Cooper Cyrus & 144 & 106,019 & Osteoporosis \& Osteoarthritis \& Epidemiology \\
Stephen R Lord & 93 & 91,427 & Falls in Older People \\
Jeffrey M Hausdorff & 76 & 28,247 & Gait \& Neurodynamic \\
Catherine Sherrington & 52 & 11,620 & Health \& Exercise \& falls \& Ageing \& \\
Keith D Hill & 44 & 6778 & Rehabilitation \\
Teresa Liu-Ambrose & 41 & 5789 & Falls prevention \& Exercise \& Rehabilitation \\
Jacqueline C T Close & 40 & 6746 & Fall prevention \& Healthy aging \\
Kim Delbaere & 38 & 4792 & Gait \& Gerontology \& Geriatric Assessment \\
Clemens Becker & 36 & 4654 & Ageing \& Accidental falls \& Fear of falling \& \\
Jorunn L Helbostad & 31 & 3476 & Falls \& Exercise \& Rehabilitation \\
Minoru Yamada & 28 & 2501 & Movement disorders and falls at old age \\
Mirjam Pijnappels & 28 & 2787 & Gerontology \& Rehabilitation \\
Noriaki Ichihashi & 26 & 2192 & The effects of aging on neuromuscular and \\
Lindy Clemson & 25 & 2972 & Rehabilitation \& Physical therapy \\
Kazuki Uemura & 23 & 1802 & Ageing \& Occupational Therapy \\
Koutatsu Nagai & 17 & 816 & Rehabilitation \& Welfare engineering \\
Anne-Marie Hill & 16 & Gerontology \& Physical Therapy \\
\hline
\end{tabular}

\subsection{Keyword Cluster Analysis}

\subsubsection{Keyword Analysis}

Keyword frequency analysis helps clarify the research trends on falls in older adults. Risk, balance, mortality, and prevalence were relatively high with frequencies of more than 2000 times, and prevention, gait, injury, women, exercise, hip fracture, community, quality of life, exercise, fracture, care, and management were relatively high with frequencies over 1000 times.

\subsubsection{Keyword Cluster Analysis}

We ran CiteSpace, generating a network as usual: 2010-2020, Slice length: 1 year; Node Select the node type: Keyword; Top N = 100 and choice Pathfinder and Pruning the merged network. Given the co-occurrence of keywords, the nodes were revised, and the Log-likelihood (LLR) algorithm was adopted for clustering calculation. The visualization map obtained $\mathrm{N}=147, \mathrm{E}=150$ (density $=0.014$ ), the Modularity Q score was 0.8423 , the Mean Silhouette score was 0.6805 , as presented in Figure 4.

There was a total of 20 clusters, mainly including 14 clusters, as listed in Table 4. Research topics regarding falls in older adults can be separated into two main topics. The first topic is risk factors that may cause accidental falls (e.g., \#1 osteoporosis, \#10 dementia, \#13 fear of falling). The other one refers to intervention to prevent falls (e.g., \#11 exercise, \#12 vitamin D).

\subsubsection{Research Hot Spots and Path Analysis}

A timeline visualization depicts clusters along a horizontal timeline. The main 14 clusters are presented in Figure 5. Each one can indicate the evolution of research in the field on falls in older adults from 2010 to 2020. 


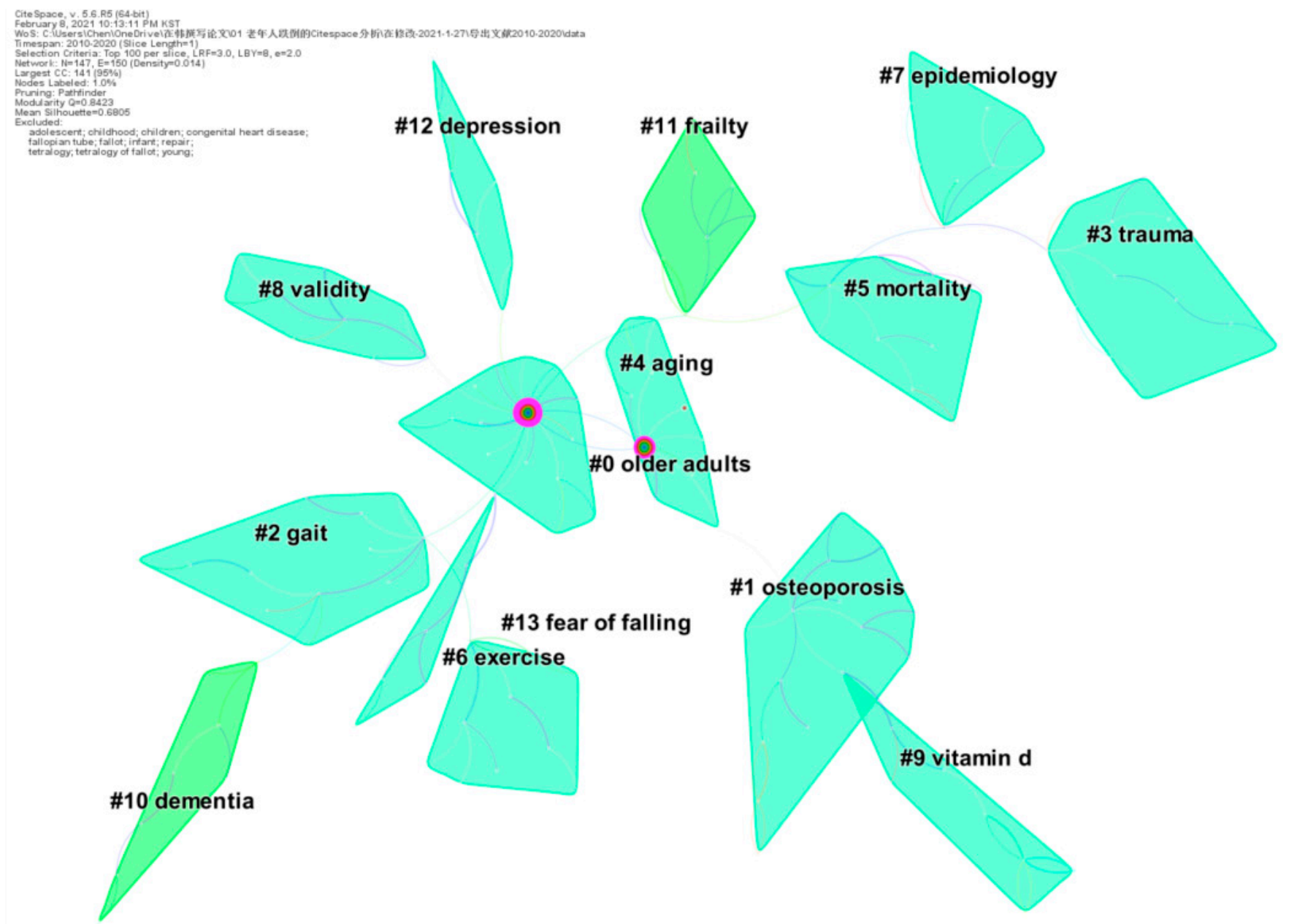

Figure 4. A landscape view of keyword cluster analysis generated by Top $N=100$ per slice from 2010 to 2020 . (LRF $=3$, $\mathrm{LBY}=8$, and $\mathrm{e}=2.0$ ).

Table 4. Subjects of cluster analysis (2010-2020).

\begin{tabular}{|c|c|c|c|}
\hline Clusters & Silhouette & Size & Log-Likelihood (LLR) \\
\hline$\# 0$ older adults & 15 & 1 & Risk factor, mobility, pain, prevention, quality of life \\
\hline \#1 osteoporosis & 14 & 0.968 & Fall detection, bone mineral density, classification, machine learning, fracture, wearable sensors \\
\hline \#2 gait & 13 & 0.985 & Balance, walking, postural control, variability, parkinsons disease, gait analysis \\
\hline \#3 trauma & 12 & 0.966 & Injury, impact, emergency department, frailty, suicide \\
\hline \#4 aging & 11 & 1 & Hip fracture, falls, vitamin d supplementation, prescription, Romberg test \\
\hline \#5 mortality & 11 & 1 & Blood pressure, survival, surgery, hypertension, morbidity, disease \\
\hline \#6 exercise & 10 & 0.971 & Physical activity, health, intervention, randomized controlled trial, fitness, social participation \\
\hline \#7 epidemiology & 9 & 0.956 & Traumatic brain injury, management, trend, diagnosis, rehabilitation \\
\hline \#8 validity & 9 & 0.967 & Reliability, women health, knee pain, lower extremity, inertial sensors, practice guidelines \\
\hline \#9 vitamin d & 8 & 1 & Sarcopenia, fractures, physical performance, obesity, muscle strength, osteosarcopenia, \\
\hline \#10 dementia & 8 & 0.966 & Cognitive impairment, polypharmacy, motoric cognitive risk syndrome, attention, long-term care \\
\hline \#11 frailty & 8 & 0.952 & Care, quality, patient, comprehensive geriatric assessment, disability, \\
\hline \#12 depression & 7 & 0.96 & Prevalence, population, mental health, sleep quality, behavior, anxiety, \\
\hline \#13 fear of falling & 6 & 0.918 & Efficacy, safety, exercise, nurses, fear, physical activity monitoring \\
\hline
\end{tabular}




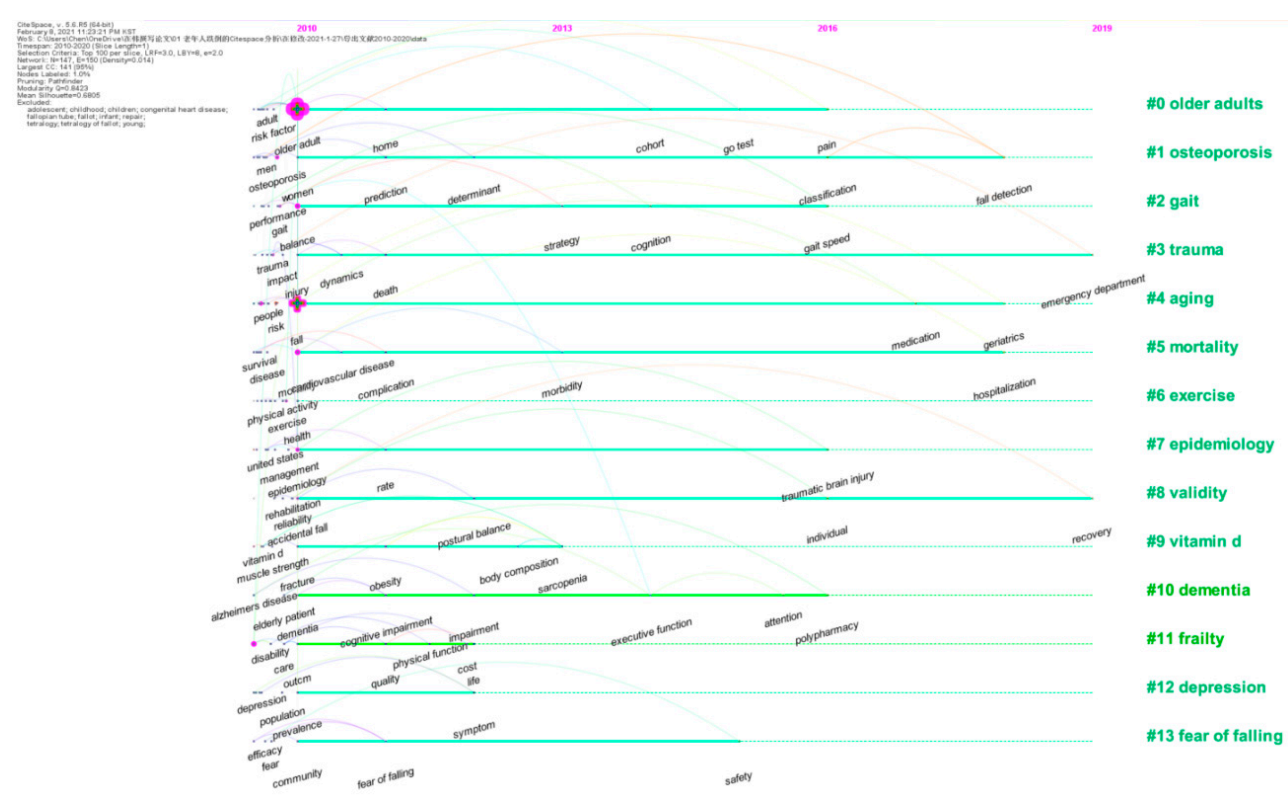

Figure 5. A timeline of the 14 largest clusters in accidental falls in older adults (2010-2020).

\subsubsection{Keywords Citation Bursts Analysis}

Citation burst refers to keywords appearing suddenly in a short period or which usage frequency increases sharply. Overall, it reveals the evolution of the research topic in different periods, as listed in Table 5.

Table 5. 38 Keywords with the strongest citation bursts (2010-2020).

\begin{tabular}{|c|c|c|c|c|c|}
\hline Keywords & Year & Strength & Begin & End & 2010-2020 \\
\hline vitamin $\mathrm{d}$ & 2010 & 25.7615 & 2010 & 2013 & - \\
\hline infection & 2010 & 34.6606 & 2010 & 2012 & \\
\hline double blind & 2010 & 22.0649 & 2010 & 2011 & - \\
\hline growth & 2010 & 4.5875 & 2010 & 2012 & - \\
\hline history & 2010 & 36.0171 & 2010 & 2013 & \\
\hline community & 2010 & 10.2497 & 2010 & 2011 & - \\
\hline guideline & 2010 & 30.1278 & 2010 & 2013 & عـــ \\
\hline hypertension & 2010 & 28.7127 & 2010 & 2015 & \\
\hline randomized controlled trial & 2010 & 16.4364 & 2010 & 2011 & - \\
\hline older people & 2010 & 55.1187 & 2010 & 2014 & \\
\hline postmenopausal women & 2010 & 16.4984 & 2010 & 2012 & - \\
\hline bone mineral density & 2010 & 2.6016 & 2010 & 2011 & - \\
\hline older women & 2010 & 31.0928 & 2010 & 2013 & \\
\hline dynamics & 2010 & 26.5791 & 2011 & 2012 & \\
\hline home & 2010 & 48.2979 & 2011 & 2014 & \\
\hline follow up & 2010 & 16.818 & 2012 & 2017 & - \\
\hline controlled trial & 2010 & 23.878 & 2012 & 2013 & - \\
\hline postural balance & 2010 & 15.4265 & 2012 & 2017 & \\
\hline rate & 2010 & 25.3309 & 2013 & 2014 & - \\
\hline body composition & 2010 & 32.8776 & 2013 & 2014 & \\
\hline prediction & 2010 & 2.6749 & 2013 & 2014 & - \\
\hline fall prevention & 2010 & 25.6649 & 2013 & 2014 & - \\
\hline consequence & 2010 & 27.3192 & 2014 & 2015 & - \\
\hline cohort & 2010 & 43.2065 & 2014 & 2018 & \\
\hline safety & 2010 & 28.2582 & 2015 & 2016 & - \\
\hline attention & 2010 & 33.7397 & 2016 & 2017 & - \\
\hline experience & 2010 & 13.7373 & 2016 & 2018 & - \\
\hline pain & 2010 & 28.5537 & 2016 & 2018 & - \\
\hline individual & 2010 & 33.4865 & 2016 & 2020 & $\ldots$ \\
\hline trial & 2010 & 9.7152 & 2016 & 2017 & - \\
\hline symptom & 2010 & 32.2689 & 2016 & 2020 & - \\
\hline gait speed & 2010 & 23.6379 & 2016 & 2017 & - \\
\hline life & 2010 & 16.1569 & 2017 & 2018 & - \\
\hline classification & 2010 & 37.0551 & 2018 & 2020 & \\
\hline fall detection & 2010 & 48.4538 & 2018 & 2020 & \\
\hline $\cos t$ & 2010 & 16.6557 & 2018 & 2020 & \\
\hline hospitalization & 2010 & 37.8174 & 2018 & 2020 & \\
\hline gender & 2010 & 27.1045 & 2018 & 2020 & \\
\hline
\end{tabular}

z-: shows which period the citation burst is the strongest. For instance, the postural balance has the longest period of burst from 2012 to 2017. 


\section{Discussion}

\subsection{Main Research Scholars' Views}

Age-related anatomic and functional changes in perception, neuromuscular function, and cognitive systems impair the control of balance and gait. Targeted training can improve muscle strength, balance, gait, mobility, while preventing falls in older adults [12], so fall prevention programs should be tailored to older adults' level of physical well-being [13].

Postmenopausal women aged over 50 are at an increased risk of developing sarcopenia and osteoporosis. Accordingly, healthy lifestyle measures in women aged over 50 are essential for healthy aging [14]. Besides, the combination of optimal protein intake and exercise leads to a greater degree of benefit than either intervention alone.

Osteosarcopenia refers to a novel syndrome that often commonly appears in a frail subset of older adults. Combined with pharmacological, nutritional, and exercise-based interventions, it should enable a more comprehensive approach to mitigate osteosarcopenia in the future [15].

Exercise and fall prevention interventions should combine with special cultures and positively exploit the support from society, physicians, and families [16]. Health care professionals should routinely discuss fall prevention with older adults, provide evidencebased advice during consultations, and follow up with referrals [17]. In addition, dual-task training, cognitive-motor training, reactive step training, and multicomponent exercise programs can effectively improve executive cognitive, gait performance, and quality of life [18], as well as lower the rates of falls and fall-related fractures [19,20]. An environmental intervention perspective combined with adequate follow-up can successfully reduce community-dwelling older adults' falls [21].

\subsection{Main Clusters Analysis}

\#1 Osteoporosis. Osteoporosis is a silent disease until a fracture occurs, which has widely developed as a worldwide health problem for men and women aged over 50 . Lumbar muscle strength and the presence of osteoporosis are endogenous factors of the risk of falls [22]. Compared with women without osteoporosis, women with postmenopausal osteoporosis had a history of one or more falls in the past year and were at a higher risk of recurrent falls so that at-risk populations should be identified through early diagnosis and treatment [22]. Balance training may significantly reduce the frequency of falls in osteoporosis patients [23]. Activities aimed at developing muscle strength, body balance, and improving intrinsic receptive sensation should be encouraged [24]. The potential consequences of severe osteoporosis can be mitigated by pharmacological therapies and the proper selection of modalities [25].

\#2 Gait and \#13 Fear of falling. These are common with advancing age. Decreased attention while walking is a significant risk factor for falls among community-dwelling older adults. Impairments in balance and gait are critical to older adults because they jeopardize the independence and contribute to the risk of falls and injuries [26]. A cut-off gait speed of $1.0 \mathrm{~m} / \mathrm{s}$ can be a useful tool to identify individuals who are high-risk individuals and evaluate preventive interventions [27]. The number of medications was associated with a decrease in gait performance. Each additional medication up-regulates the risk of gait decline by $12 \%$ to $16 \%$ [28]. A history of falls in the previous year was a good predictor of the fear of falling, and fear of falling is an independent risk factor for falls in older adults. Falls Efficacy Scale-International (FES-I) and Tinetti's Falls Efficacy Scale are reliable and valid to measure the fear of falling $[29,30]$. Whether exercise interventions reduce the fear of falling beyond the end of the intervention has been insufficiently evidenced [31].

\#3 Trauma and \#5 Mortality. Research on traumatic brain injury (TBI) has increased over the past two decades [32]. TBI is the main cause of emergency department visits in older adults, which is a significant part of the overall injury burden [33]. The major consequences of TBI are hip fractures and intracranial injury, which account for $46 \%$ of fatal falls in older adults [34]. Moreover, TBI arising from closed head trauma (CHT) significantly increases the risk of developing Alzheimer's disease (AD), Parkinson's disease 
(PD), and chronic traumatic encephalopathy (CTE) [35], and these would increase the risk of fall-related injuries in older adults. The incidence of TBI may continue to increase over time. Trauma patients with these risk factors may require higher professional health care levels and should be enrolled in a formally fall prevention program [36]. Moreover, trauma in older adults should be addressed from a public health vision with improved social service quality and prevention. Falls are a significant cause of mortality in older adults [37]. Unintentional falls continued to be a major cause of death (29\%) in China [38]. The trend in mortality from falls was similarly observed increasing among US and European data [39-42]. The fall-related mortality in Japanese older adults aged 65-74 years showed a more rapid and continuous decreasing trend, but men over 75 years did not decrease [43].

\#4 Aging and \#11 Frailty. With the increasing older adult population, frailty is an important health care topic for people with geriatric syndromes. The effect of satisfaction with aging as a potential protective mechanism against fall results in reducing the risk for falls [44]. Frailty and pre-frailness are significantly associated with a higher risk of fracture, disability, and falls [45]. The future fall risk attributed to frailty was suggested to be higher in men than in women [46]. Accordingly, older adults should be evaluated for the possibility of geriatric syndromes to lower the risk of falls, fractures, or death.

\#6 Exercise and \#9 Vitamin D. Exercise programs reduce the rate of falls. An exercise program primarily involves balance and functional training [9], while a program includes multiple types of exercise (usually balance and functional exercises and resistance exercises) [47]; Otago exercise program, high-intensity interval training (HIIT), or virtual reality (VR) will have more significantly reduced the fall rate [48-50]. The interaction of exercise and various nutrients, especially protein and some multi-nutritional supplements, influenced muscle and bone health in older adults. Low levels of vitamin D have been associated with increased fall rates. However, no consistent conclusion has been reached for the relationship between vitamin D deficiency and these broader health outcomes [51], including daily oral doses of vitamin D [52-54]. Subsequent research should be conducted to determine the role of vitamin $\mathrm{D}$ in the relationship with falls in older adults.

One point that needs to be emphasized is that most countries have taken active interventions to prevent falls in older adults, significantly reducing the rate of falls in older adults. However, our society still lacks awareness of sarcopenia (Table 4 \#9). The underlying mechanism of sarcopenia remains unclear, and no widely accepted definitions are suitable for use in research and clinical settings, and methodological challenges and debates are ongoing [55]. Sarcopenia has been associated with aging and older adults, but the development of sarcopenia now can also possibly occur earlier in life [56], so this study attempted to give a brief introduction to sarcopenia.

In 1989, Irwin Rosenberg proposed the theory of sarcopenia. In 2016, the ICD-10-MC Diagnosis Code officially identified sarcopenia as a muscle disease [57]. In 2010, the European Working Group on Sarcopenia in Older People (EWGSOP) developed practical clinical definitions and consensus diagnostic criteria [56] and updated the definition of myasthenia gravis by exploiting the last decade's research and accumulated clinical evidence in 2018 [58]. The Asian Sarcopenia Working Group (AWGS) defined the diagnostic sarcopenia criteria by referencing Asian data in 2014 [59], while diagnostic procedures, protocols, and some metrics were revised in 2019 [60]. Both the Foundation for the National Institutes of Health (FNIH) and the International Working Group on Sarcopenia (IWGS) also have their definitions of sarcopenia. Thus, research based on different definitions may be misleading and difficult to interpret, such as cutoff point, diagnostic procedures, and so on.

Here, the definition of sarcopenia by the EWGSOP 2 is taken as an example. Sarcopenia is a progressive and generalized skeletal muscle disorder that is associated with an increased likelihood of adverse outcomes including falls, fractures, physical disability, and mortality [58]. Nutritional, inactivity, disease, iatrogenic may be the most frequent underlying causes of sarcopenia [61]. Specifically, sarcopenia is probable when low muscle strength is detected. A sarcopenia diagnosis is confirmed by the presence of low muscle 
quantity or quality. When low muscle strength, low muscle quantity/quality, and low physical performance are all detected, sarcopenia is considered severe. Subsequently, studies found that, when untreated, sarcopenia can bring a high personal, social, and economic burden [62]. For human health, sarcopenia can elevate the risk of falls and fractures [63], impairing the ability to perform activities of daily living [64], as well as raising the risk of hospitalization.

Lifestyle interventions, especially exercise and nutritional supplementation, prevail as mainstays of treatment. Subsequent research is required to investigate the potential long-term benefits of lifestyle interventions, nutritional supplements, or pharmacotherapy for sarcopenia. Moreover, several questions should be studied in-depth, including how to identify the high risk of sarcopenia early, what makes sarcopenia worse, which muscle indicators can be the most effective predictors of adverse outcomes, how we can optimally assess the muscle mass, how to determine effective critical value, which measurement tools are the most accurate, what interventions are available for sarcopenia, as well as which intervention should be the first choice.

\#7 Epidemiology and \#8 Validity. The incidence of falls and related complications increases with age. Furthermore, the epidemiology of falls in the incidence for women was higher than men. The rate of falls in community-dwelling adults is lower than in long-term care institutions. Most community-dwelling falls lead to about $5 \%$ fracture or hospitalization, and those in long-term institutions tend to more serious, with 10-25\% of such falls resulting in fracture or laceration. Wrist fractures are common between the ages of 65 and 75, while hip fractures predominate after age 75 [5]. Wrist fractures usually result from falls forward or backward on an outstretched hand and hip fractures typically from falls to the side [65]. A lot of fall assessment tools have been developed and designed for different purposes over recent decades, most of them are targeted at assessing geriatric patients and have been available on reliability and validity [66]. But patient fall risk scales more focus on specific intrinsic and extrinsic factors, it could not fully assess a patient's current fall risk status, which needs more patient-centered assessments and interventions [67].

\#10 Dementia and \#12 Depression. People with various levels of cognitive impairment can benefit from supervised multimodal exercise to improve physical function [68]. With the incidence of dementia growing globally, people with dementia are at a higher risk of falls and fall-related injuries, while there is still an argument about the exercise intervention for dementia patients [69]. There is little evidence about the effect of specific types of exercise on dementia risk [70]. More high-quality intervention studies should be conducted to inform evidence-practice initiatives. Depression is associated with the incidence of dementia, with a variety of possibly psychological or physiological mechanisms. Depression and falls are common and co-exist. Geriatric depression score (GDs) was used as a significant predictor of older adults from falls. Depression treatment should be incorporated in fall prevention programs for older adults at a high risk of increasing/multiple falls. Based on the existing state of knowledge, exercise (especially tai chi) and cognitive behavioral therapy should be considered to treat mild depression in older fallers [71].

\subsection{Keywords Citation Bursts}

According to Table 5, hypertension and postmenopausal women have attracted widespread attention at first. In postmenopausal women, due to insufficient estrogen, osteoporosis affects bone formation and increases the risk of falls. Women have caught the attention of scholars, and studies had proved that exercise training for postmenopausal women is an effective approach to improve fall or fracture [72]. The studies conducted between 2010-2015 on links between hypertension and falls are also of high significance. It is known that the increased risk of falls due to hypertension is related to the use of antihypertensive drugs, vascular sclerosis, and poor gait performance. Accordingly, nursing and intervention guidance should be strengthened to prevent patients with hypertension falls. With studies conducted in-depth, bone mineral density, postural balance, and body 
composition became research hotspots, and then gradually turned to fall prevention and prediction. Note that fall detection, classification, hospitalization, cost, and gender are receiving more attention.

A fall detection system by exploiting the Internet of Things can reduce the serious consequences of falls [73], which has made important progress in novel sensors, technologies, and algorithms [74]. However, there are two main challenges facing fall detection systems. One is to identify when a serious fall takes place, the other one refers to the lack of real data on falls to improve the research. Furthermore, how to apply laboratory data to real life, how to protect user privacy, and how to shift from detecting falls to predicting falls are recognized as the novel directions of development [75]. The classification of falls and the incidence of falls in different settings, socio-demographic determinants, international trends, and the measurement of fall outcomes, including the costs of falls and fall-related injuries, are the hot topics [76]. Costs generated by falls are expected to increase with the rapid expansion of the aging population. These costs fall into two parts. One is direct costs including health care costs (e.g., medications), while the other is treatment and consultations for rehabilitation, i.e., losses in societal productivity of activities for individuals and caregivers [77]. Occupational therapy had the effectiveness and cost-effectiveness in improving functional ability and decrease hospital readmission for older adults [78]. Risk factors for falls vary with gender [79]. Gender should be considered in the design of fall prevention strategies [80].

\section{Conclusions}

First, studies on falls in older adults have been increasingly conducted in the 21st century; the number of papers published every year is increasing. The mentioned findings suggest that when setting the selection criteria for Top $N=20$, Cooper Cyrus, Stephen $\mathrm{R}$ Lord, Minoru Yamada, and Catherine Sherrington play an important role in the study of falls in older adults. The University of Sydney (Australia) has published the largest number of papers on falls in older adults, and the most obvious burst in the present study is Harvard Medical School (USA). The University of Oxford (USA) was the most central institution. The highest Sigma $\left(\sum\right)$ is The University of Pittsburgh (USA).

Second, Geriatrics Gerontology, Medical General Internal, Clinical Neurology, Clinical Neurology, Neurosciences, Orthopedics, Rehabilitation, Surgery, Sport Sciences, Public Environmental Occupational Health and Gerontology are considered the main research scopes involved in falls. The journals PloS One, Gait \& Posture, and BMC Geriatrics were the top 3 journals regarding accidental falls in older adults.

Third, osteoporosis, dementia, sarcopenia, hypertension, traumatic brain injury, frailty, depression, fear of falling would be significantly correlated with falls in older adults. Nowadays, fall detection, hospitalization, classification, gender, and cost are the focus and direction of the development of falls in older adults.

Fourth, age-related changes in perception, neuromuscular, and cognitive systems interfere with the control of balance and gait. Fall prevention programs should be tailored to the older adult's level of physical well-being. Targeted training can improve muscle strength, balance, gait, and mobility while preventing falls in older adults. A program consisting of multiple types of exercise, HIIT, or VR may more significantly reduce the fall rate of older adults than a single exercise intervention.

Falling is a serious issue concerned with the health of older adults, which affects the physical and mental health and quality of life for themselves and their families. Only one-third of all older adults who fell have sought medical assistance; one possible reason is the lack of public awareness about the importance of fall prevention [81]. This study introduces the last decade of research results on fall-related factors from different aspects such as physiology, pathology, psychology, environment, and sports science expounds on the latest developments in this aspect of research and relevant experts' opinions are summarized, enabling more people to gain comprehensive insights into falls of older adults to prevent or reduce older adults from fall-related injuries. Moreover, a good peer view is 
presented for the study using scientific methods to find good methods to prevent, treat or reduce the risk of falls. There are some limitations to the study. For instance, the selected papers were only included in the Web of Science Core Collection, and searches are not selected in PubMed, Scopus, or other databases. Besides, the literature contains papers in English only; the status of research on falls in older adults in other language nations is not possible to determine. Lastly, CiteSpace analysis is biased towards quantitative analysis. In subsequent studies, the qualitative research method of the interview method should be adopted to remedy the defects of quantitative research. Though further research is needed, this preliminary result may give a new horizon for fall prevention.

Author Contributions: Conceptualization, B.C. and S.S.; methodology, B.C.; software, S.S.; validation, S.S.; investigation, S.S.; writing—original draft preparation, B.C.; writing-review and editing, S.S.; visualization, B.C.; supervision, S.S.; project administration, S.S. All authors have read and agreed to the published version of the manuscript.

Funding: This work was supported by the 2020 Research Fund of University of Ulsan.

Institutional Review Board Statement: Not applicable.

Informed Consent Statement: Not applicable.

Data Availability Statement: Not applicable.

Conflicts of Interest: The authors declare no conflict of interest.

\section{Appendix A. Web of Science Core Collection}

Table A1. Search history from Web of Science Core Collection.

\begin{tabular}{|c|c|c|}
\hline Set & Results & \\
\hline \multirow{2}{*}{$\# 10$} & \multirow{2}{*}{34,899} & \#9 AND \#6 \\
\hline & & Indexes=SCI-EXPANDED, SSCI, A\&HCI, CPCI-S, CPCI-SSH, BKCI-S, BKCI-SSH, ESCI, CCR-EXPANDED, IC Timespan=2010-2020 \\
\hline \multirow{2}{*}{$\# 9$} & \multirow{2}{*}{$1,834,798$} & \#18 OR \#17 \\
\hline & & Indexes=SCI-EXPANDED, SSCI, A\&HCI, CPCI-S, CPCI-SSH, BKCI-S, BKCI-SSH, ESCI, CCR-EXPANDED, IC Timespan=2010-2020 \\
\hline \multirow{2}{*}{ \#8 } & \multirow{2}{*}{134,166} & TOPIC: (Elderly) AND DOCUMENT TYPES: (Article OR Review) AND LANGUAGE: (English) \\
\hline & & Indexes=SCI-EXPANDED, SSCI, A\&HCI, CPCI-S, CPCI-SSH, BKCI-S, BKCI-SSH, ESCI, CCR-EXPANDED, IC Timespan=2010-2020 \\
\hline \multirow{2}{*}{$\# 7$} & \multirow{2}{*}{$1,784,189$} & TOPIC: (Aged) AND DOCUMENT TYPES: (Article OR Review) AND LANGUAGE: (English) \\
\hline & & Indexes=SCI-EXPANDED, SSCI, A\&HCI, CPCI-S, CPCI-SSH, BKCI-S, BKCI-SSH, ESCI, CCR-EXPANDED, IC Timespan=2010-2020 \\
\hline \multirow{2}{*}{ \#6 } & \multirow{2}{*}{181,751} & \#5 OR \#4 OR \#3 OR \#2 OR \#1 \\
\hline & & Indexes=SCI-EXPANDED, SSCI, A\&HCI, CPCI-S, CPCI-SSH, BKCI-S, BKCI-SSH, ESCI, CCR-EXPANDED, IC Timespan=2010-2020 \\
\hline \multirow{2}{*}{$\# 5$} & \multirow{2}{*}{73} & TOPIC: ("Slip and Fall") AND DOCUMENT TYPES: (Article OR Review) AND LANGUAGE: (English) \\
\hline & & Indexes=SCI-EXPANDED, SSCI, A\&HCI, CPCI-S, CPCI-SSH, BKCI-S, BKCI-SSH, ESCI, CCR-EXPANDED, IC Timespan=2010-2020 \\
\hline \multirow{2}{*}{$\# 4$} & \multirow{2}{*}{3} & TOPIC: ("Fall and Slip") AND DOCUMENT TYPES: (Article OR Review) AND LANGUAGE: (English) \\
\hline & & Indexes=SCI-EXPANDED, SSCI, A\&HCI, CPCI-S, CPCI-SSH, BKCI-S, BKCI-SSH, ESCI, CCR-EXPANDED, IC Timespan=2010-2020 \\
\hline \multirow{2}{*}{$\# 3$} & \multirow{2}{*}{16} & TOPIC: ("Fall*, Accidental") AND DOCUMENT TYPES: (Article OR Review) AND LANGUAGE: (English) \\
\hline & & Indexes=SCI-EXPANDED, SSCI, A\&HCI, CPCI-S, CPCI-SSH, BKCI-S, BKCI-SSH, ESCI, CCR-EXPANDED, IC Timespan=2010-2020 \\
\hline \multirow{2}{*}{$\# 2$} & \multirow{2}{*}{181,751} & TOPIC: (Fall*) AND DOCUMENT TYPES: (Article OR Review) AND LANGUAGE: (English) \\
\hline & & Indexes=SCI-EXPANDED, SSCI, A\&HCI, CPCI-S, CPCI-SSH, BKCI-S, BKCI-SSH, ESCI, CCR-EXPANDED, IC Timespan=2010-2020 \\
\hline \multirow{2}{*}{$\# 1$} & \multirow{2}{*}{1704} & TOPIC: ("Accidental Fall") AND DOCUMENT TYPES: (Article OR Review) AND LANGUAGE: (English) \\
\hline & & Indexes=SCI-EXPANDED, SSCI, A\&HCI, CPCI-S, CPCI-SSH, BKCI-S, BKCI-SSH, ESCI, CCR-EXPANDED, IC Timespan=2010-2020 \\
\hline
\end{tabular}

\section{Appendix B. PubMed}

Search: ((“Accidental Falls”[Mesh]) OR ((((((Falls[Title/Abstract]) OR (Falling[Title/Abstract])) OR ("Falls, Accidental"[Title/Abstract])) OR ("Falls, Accidental"[Title/Abstract])) OR ("Fall, Accidental"[Title/Abstract])) OR ("Slip[Title/Abstract] AND Fall"[Title/Abstract])) OR ("Fall[Title/Abstract] AND Slip"[Title/Abstract]))) AND ((“Aged"[Mesh]) OR (Elderly[Title/Abstract])) Filters: Journal Article, Review, English, Humans, from 2010/1/12020/12/31. 


\section{Appendix C. Embase}

Table A2. Search history from Embase.

\begin{tabular}{|c|c|c|}
\hline Set & & Results \\
\hline$\# 8$ & $\begin{array}{l}\text { \#3 AND \#6 AND ([article]/lim OR [review]/lim) AND } \\
\text { [english]/lim AND [humans]/lim AND [2010-2020]/py }\end{array}$ & 15,588 \\
\hline$\# 7$ & \#3 AND \#6 & 33,343 \\
\hline$\# 6$ & \#4 OR \#5 & $3,293,154$ \\
\hline$\# 5$ & 'elderly':ab,ti & 356,182 \\
\hline$\# 4$ & 'aged'/exp & $3,213,541$ \\
\hline$\# 3$ & \#1 OR \#2 & 90,715 \\
\hline$\# 2$ & $\begin{array}{l}\text { 'falls':ab,ti OR 'accidental falls':ab,ti OR 'falls, accidental':ab,ti OR } \\
\text { 'accidental fall':ab,ti OR 'fall, accidental':ab,ti }\end{array}$ & 67,327 \\
\hline$\# 1$ & 'falling' /exp & 41,962 \\
\hline
\end{tabular}

\section{Appendix D. Scopus}

((TITLE-ABS-KEY (“accidental fall*”) OR TITLE-ABS-KEY (fall*) OR TITLE-ABS-KEY (falling) OR TI-TLE-ABS-KEY ("Fall*, Accidental") OR TITLE-ABS-KEY ("Slip and Fall”) OR TITLE-ABS-KEY (“Fall and Slip”))) AND ((TITLE-ABS-KEY (aged) OR TITLE-ABS-KEY (elderly))) AND (LIMIT-TO (DOCTYPE, "ar") OR LIMIT-TO (DOCTYPE, "re")) AND (LIMITTO (PUBYEAR, 2020) OR LIMIT-TO (PUBYEAR, 2019) OR LIMIT-TO (PUBYEAR, 2018) OR LIMIT-TO (PUBYEAR, 2017) OR LIMIT-TO (PUBYEAR, 2016) OR LIMIT-TO (PUBYEAR, 2015) OR LIMIT-TO (PUBYEAR, 2014) OR LIMIT-TO (PUBYEAR, 2013) OR LIMIT-TO (PUBYEAR, 2012) OR LIMIT-TO (PUBYEAR, 2011) OR LIMIT-TO (PUBYEAR, 2010)) AND (LIMIT-TO (LANGUAGE, “English")) AND (LIMIT-TO (SRCTYPE, "j")) AND (LIM-IT-TO (EXACTKEYWORD, "Human") OR LIMIT-TO (EXACTKEYWORD, “Humans")).

\section{References}

1. Kohl, H.W., 3rd; Craig, C.L.; Lambert, E.V.; Inoue, S.; Alkandari, J.R.; Leetongin, G.; Kahlmeier, S.; Lancet Physical Activity Series Working, G. The pandemic of physical inactivity: Global action for public health. Lancet 2012, 380, 294-305. [CrossRef]

2. Qato, D.M.; Wilder, J.; Schumm, L.P.; Gillet, V.; Alexander, G.C. Changes in prescription and over-the-counter medication and dietary supplement use among older adults in the United States, 2005 vs. 2011. JAMA Intern. Med. 2016, 176, 473-482. [CrossRef]

3. Bergen, G.; Stevens, M.R.; Burns, E.R. Falls and Fall Injuries Among Adults Aged $\geq 65$ Years—United States, 2014. MMWR Morb. Mortal. Wkly. Rep. 2016, 65, 993-998. [CrossRef] [PubMed]

4. Ambrose, A.F.; Paul, G.; Hausdorff, J.M. Risk factors for falls among older adults: A review of the literature. Maturitas 2013, 75, 51-61. [CrossRef] [PubMed]

5. Rubenstein, L.Z. Falls in older people: Epidemiology, risk factors and strategies for prevention. Age Ageing 2006, 35, 37-41. [CrossRef] [PubMed]

6. Boelens, C.; Hekman, E.E.G.; Verkerke, G.J. Risk factors for falls of older citizens. Technol. Health Care 2013, 21, 521-533. [CrossRef] [PubMed]

7. Florence, C.S.; Bergen, G.; Atherly, A.; Burns, E.; Stevens, J.; Drake, C. The medical costs of fatal falls and fall injuries among older adults. J. Am. Geriatr. Soc. 2018, 66, 693-698. [CrossRef] [PubMed]

8. Ng, C.; Fairhall, N.; Wallbank, G.; Tiedemann, A.; Michaleff, Z.A.; Sherrington, C. Exercise for falls prevention in communitydwelling older adults: Trial and participant characteristics, interventions and bias in clinical trials from a systematic review. BMJ Open Sport Exerc. Med. 2019, 5, e000663. [CrossRef]

9. Sherrington, C.; Fairhall, N.J.; Wallbank, G.K.; Tiedemann, A.; Michaleff, Z.A.; Howard, K.; Clemson, L.; Hopewell, S.; Lamb, S.E. Exercise for preventing falls in older people living in the community. Cochrane Database Syst. Rev. 2019, 1, CD012424. [CrossRef]

10. Jianhua, H.; Zhigang, H. Review on the application of citespace at home and abroad. J. Mod. Inf. Ser. 2013, 33, 99-103.

11. Chen, Y.; Chen, C.; Liu, Z.; Hu, Z.; Wang, X. The methodology function of CiteSpace mapping knowledge domains. Stud. Sci. Sci. 2015, 33, 242-253.

12. Lord, S.R.; Delbaere, K.; Sturnieks, D.L. Aging. Handb. Clin. Neurol. 2018, 159, 157-171. [CrossRef] [PubMed]

13. Yamada, M. Tailor-made programs for preventive falls. Jpn. J. Clin. Med. 2014, 72, 1821-1826. 
14. Rizzoli, R.; Stevenson, J.C.; Bauer, J.M.; van Loon, L.J.; Walrand, S.; Kanis, J.A.; Cooper, C.; Brandi, M.L.; Diez-Perez, A.; Reginster, J.Y.; et al. The role of dietary protein and vitamin D in maintaining musculoskeletal health in postmenopausal women: A consensus statement from the European Society for Clinical and Economic Aspects of Osteoporosis and Osteoarthritis (ESCEO). Maturitas 2014, 79, 122-132. [CrossRef] [PubMed]

15. Paintin, J.; Cooper, C.; Dennison, E. Osteosarcopenia. Br. J. Hosp. Med. (Lond.) 2018, 79, 253-258. [CrossRef] [PubMed]

16. Jang, H.; Clemson, L.; Lovarini, M.; Willis, K.; Lord, S.R.; Sherrington, C. Cultural influences on exercise participation and fall prevention: A systematic review and narrative synthesis. Disabil. Rehabil. 2016, 38, 724-732. [CrossRef]

17. Lee, D.C.; Day, L.; Hill, K.; Clemson, L.; McDermott, F.; Haines, T.P. What factors influence older adults to discuss falls with their health-care providers? Health Expect 2015, 18, 1593-1609. [CrossRef]

18. Lord, S.R.; Close, J.C.T. New horizons in falls prevention. Age Ageing 2018, 47, 492-498. [CrossRef]

19. Kayama, H.; Okamoto, K.; Nishiguchi, S.; Yamada, M.; Kuroda, T.; Aoyama, T. Effect of a Kinect-based exercise game on improving executive cognitive performance in community-dwelling elderly: Case control study. J Med. Internet Res. 2014, 16, e61. [CrossRef]

20. Yamada, M.; Aoyama, T.; Hikita, Y.; Takamura, M.; Tanaka, Y.; Kajiwara, Y.; Nagai, K.; Uemura, K.; Mori, S.; Tanaka, B. Effects of a DVD-based seated dual-task stepping exercise on the fall risk factors among community-dwelling elderly adults. Telemed. J. E Health 2011, 17, 768-772. [CrossRef]

21. Clemson, L.; Mackenzie, L.; Ballinger, C.; Close, J.C.; Cumming, R.G. Environmental interventions to prevent falls in communitydwelling older people: A meta-analysis of randomized trials. J. Aging Health 2008, 20, 954-971. [CrossRef]

22. Da Silva, R.B.; Costa-Paiva, L.; Morais, S.S.; Mezzalira, R.; Ferreira Nde, O.; Pinto-Neto, A.M. Predictors of falls in women with and without osteoporosis. J. Orthop. Sports Phys. Ther. 2010, 40, 582-588. [CrossRef] [PubMed]

23. Zhou, X.; Deng, H.; Shen, X.; Lei, Q. Effect of balance training on falls in patients with osteoporosis: A systematic review and meta-analysis. J. Rehabil. Med. 2018, 50, 577-581. [CrossRef] [PubMed]

24. Shier, V.; Trieu, E.; Ganz, D.A. Implementing exercise programs to prevent falls: Systematic descriptive review. Inj. Epidemiol. 2016, 3, 16. [CrossRef] [PubMed]

25. Miller, P.D. Management of severe osteoporosis. Expert. Opin. Pharmacother. 2016, 17, 473-488. [CrossRef] [PubMed]

26. Viswanathan, A.; Sudarsky, L. Balance and gait problems in the elderly. Handb. Clin. Neurol. 2012, 103, 623-634. [CrossRef] [PubMed]

27. Kyrdalen, I.L.; Thingstad, P.; Sandvik, L.; Ormstad, H. Associations between gait speed and well-known fall risk factors among community-dwelling older adults. Physiother. Res. Int. 2019, 24, e1743. [CrossRef]

28. Montero-Odasso, M.; Sarquis-Adamson, Y.; Song, H.Y.; Bray, N.W.; Pieruccini-Faria, F.; Speechley, M. Polypharmacy, gait performance, and falls in community-dwelling older adults. Results from the Gait and Brain Study. J. Am. Geriatr. Soc. 2019, 67, 1182-1188. [CrossRef] [PubMed]

29. Delbaere, K.; Close, J.C.; Mikolaizak, A.S.; Sachdev, P.S.; Brodaty, H.; Lord, S.R. The Falls Efficacy Scale International (FES-I). A comprehensive longitudinal validation study. Age Ageing 2010, 39, 210-216. [CrossRef] [PubMed]

30. Bosscher, R.J.; Raymakers, E.R.; Trompe, E.A.; Smit, J.H. Fear of falling: Psychometric aspects of Tinetti's Falls Efficacy Scale. Tijdschr. Gerontol. Geriatr. 2005, 36, 5-10. [CrossRef]

31. Kumar, A.; Delbaere, K.; Zijlstra, G.A.; Carpenter, H.; Iliffe, S.; Masud, T.; Skelton, D.; Morris, R.; Kendrick, D. Exercise for reducing fear of falling in older people living in the community: Cochrane systematic review and meta-analysis. Age Ageing 2016, 45, 345-352. [CrossRef]

32. Qi, B.; Jin, S.; Qian, H.; Zou, Y. Bibliometric Analysis of Chronic Traumatic Encephalopathy Research from 1999 to 2019. Int. J. Environ. Res. Public Health 2020, 17, 5411. [CrossRef] [PubMed]

33. Injury, G.B.D.T.B.; Spinal Cord Injury, C. Global, regional, and national burden of traumatic brain injury and spinal cord injury, 1990-2016: A systematic analysis for the Global Burden of Disease Study 2016. Lancet Neurol. 2019, 18, 56-87. [CrossRef]

34. Stevens, J.A.; Corso, P.S.; Finkelstein, E.A.; Miller, T.R. The costs of fatal and non-fatal falls among older adults. Inj. Prev. 2006, 12, 290-295. [CrossRef] [PubMed]

35. VanItallie, T.B. Traumatic brain injury (TBI) in collision sports: Possible mechanisms of transformation into chronic traumatic encephalopathy (CTE). Metabolism 2019, 100, 153943. [CrossRef]

36. Brown, C.V.; Ali, S.; Fairley, R.; Lai, B.K.; Arthrell, J.; Walker, M.; Tips, G. Risk factors for falls among hospitalized trauma patients. Am. Surg. 2013, 79, 465-469. [CrossRef] [PubMed]

37. Berkova, M.; Berka, Z. Falls: A significant cause of morbidity and mortality in elderly people. Vnitr. Lek. 2018, 64, 1076-1083. [PubMed]

38. Cheng, P.; Wang, L.; Ning, P.; Yin, P.; Schwebel, D.C.; Liu, J.; Qi, J.; Hu, G.; Zhou, M. Unintentional falls mortality in China, 2006-2016. J. Glob. Health 2019, 9, 010603. [CrossRef]

39. Hartholt, K.A.; Lee, R.; Burns, E.R.; van Beeck, E.F. Mortality from falls among us adults aged 75 years or older, 2000-2016. JAMA 2019, 321, 2131-2133. [CrossRef]

40. Hartholt, K.A.; van Beeck, E.F.; van der Cammen, T.J.M. Mortality from falls in dutch adults 80 years and older, 2000-2016. JAMA 2018, 319, 1380-1382. [CrossRef]

41. Padrón-Monedero, A.; Damián, J.; Pilar Martin, M.; Fernández-Cuenca, R. Mortality trends for accidental falls in older people in Spain, 2000-2015. BMC Geriatr. 2017, 17, 276. [CrossRef] [PubMed] 
42. Kiadaliri, A.A.; Rosengren, B.E.; Englund, M. Fall-related mortality in southern Sweden: A multiple cause of death analysis, 1998-2014. Inj. Prev. 2019, 25, 129-135. [CrossRef] [PubMed]

43. Hagiya, H.; Koyama, T.; Zamami, Y.; Tatebe, Y.; Funahashi, T.; Shinomiya, K.; Kitamura, Y.; Hinotsu, S.; Sendo, T.; Rakugi, H.; et al. Fall-related mortality trends in older Japanese adults aged $\geq 65$ years: A nationwide observational study. BMJ Open 2019, 9, e033462. [CrossRef] [PubMed]

44. Ayalon, L. Satisfaction with aging results in reduced risk for falling. Int. Psychogeriatr. 2016, 28, 741-747. [CrossRef] [PubMed]

45. Tom, S.E.; Adachi, J.D.; Anderson, F.A., Jr.; Boonen, S.; Chapurlat, R.D.; Compston, J.E.; Cooper, C.; Gehlbach, S.H.; Greenspan, S.L.; Hooven, F.H.; et al. Frailty and fracture, disability, and falls: A multiple country study from the global longitudinal study of osteoporosis in women. J. Am. Geriatr. Soc. 2013, 61, 327-334. [CrossRef] [PubMed]

46. Kojima, G. Frailty as a predictor of future falls among community-dwelling older people: A systematic review and meta-analysis. J. Am. Med. Dir. Assoc. 2015, 16, 1027-1033. [CrossRef]

47. Clemson, L.; Fiatarone Singh, M.A.; Bundy, A.; Cumming, R.G.; Manollaras, K.; O'Loughlin, P.; Black, D. Integration of balance and strength training into daily life activity to reduce rate of falls in older people (the LiFE study): Randomised parallel trial. BMJ 2012, 345, e4547. [CrossRef]

48. Mirelman, A.; Rochester, L.; Maidan, I.; Del Din, S.; Alcock, L.; Nieuwhof, F.; Rikkert, M.O.; Bloem, B.R.; Pelosin, E.; Avanzino, L.; et al. Addition of a non-immersive virtual reality component to treadmill training to reduce fall risk in older adults (V-TIME): A randomised controlled trial. Lancet 2016, 388, 1170-1182. [CrossRef]

49. Jiménez-García, J.D.; Hita-Contreras, F.; de la Torre-Cruz, M.; Fábrega-Cuadros, R.; Aibar-Almazán, A.; Cruz-Díaz, D.; Martínez-Amat, A. Risk of falls in healthy older adults: Benefits of high-intensity interval training using lower body suspension exercises. J. Aging Phys. Act. 2019, 27, 325-333. [CrossRef]

50. Thomas, S.; Mackintosh, S.; Halbert, J. Does the 'Otago exercise programme' reduce mortality and falls in older adults? A systematic review and meta-analysis. Age Ageing 2010, 39, 681-687. [CrossRef]

51. Holroyd, C.R.; Cooper, C.; Harvey, N.C. Vitamin D and the postmenopausal population. Menopause Int. 2011, $17,102-107$. [CrossRef] [PubMed]

52. Gallagher, J.C. Vitamin D and falls-The dosage conundrum. Nat. Rev. Endocrinol. 2016, 12, 680-684. [CrossRef] [PubMed]

53. Uusi-Rasi, K.; Patil, R.; Karinkanta, S.; Kannus, P.; Tokola, K.; Lamberg-Allardt, C.; Sievänen, H. Exercise and vitamin D in fall prevention among older women: A randomized clinical trial. JAMA Intern. Med. 2015, 175, 703-711. [CrossRef] [PubMed]

54. Bolland, M.J.; Grey, A.; Avenell, A. Effects of vitamin D supplementation on musculoskeletal health: A systematic review, meta-analysis, and trial sequential analysis. Lancet Diabetes Endocrinol. 2018, 6, 847-858. [CrossRef]

55. Dennison, E.M.; Sayer, A.A.; Cooper, C. Epidemiology of sarcopenia and insight into possible therapeutic targets. Nat. Rev. Rheumatol. 2017, 13, 340-347. [CrossRef]

56. Cruz-Jentoft, A.J.; Baeyens, J.P.; Bauer, J.M.; Boirie, Y.; Cederholm, T.; Landi, F.; Martin, F.C.; Michel, J.P.; Rolland, Y.; Schneider, S.M.; et al. Sarcopenia: European consensus on definition and diagnosis: Report of the european working group on sarcopenia in older people. Age Ageing 2010, 39, 412-423. [CrossRef]

57. Codes, I.-C. Sarcopenia. Available online: https://www.icd10data.com/ICD10CM/Codes/M00-M99/M60-M63/M62-/M62.84 (accessed on 1 October 2016).

58. Cruz-Jentoft, A.J.; Bahat, G.; Bauer, J.; Boirie, Y.; Bruyere, O.; Cederholm, T.; Cooper, C.; Landi, F.; Rolland, Y.; Sayer, A.A.; et al. Sarcopenia: Revised European consensus on definition and diagnosis. Age Ageing 2019, 48, 601. [CrossRef]

59. Chen, L.K.; Liu, L.K.; Woo, J.; Assantachai, P.; Auyeung, T.W.; Bahyah, K.S.; Chou, M.Y.; Chen, L.Y.; Hsu, P.S.; Krairit, O.; et al. Sarcopenia in Asia: Consensus report of the Asian Working Group for Sarcopenia. J. Am. Med. Dir. Assoc. 2014, $15,95-101$. [CrossRef]

60. Chen, L.K.; Woo, J.; Assantachai, P.; Auyeung, T.W.; Chou, M.Y.; Iijima, K.; Jang, H.C.; Kang, L.; Kim, M.; Kim, S.; et al. Asian Working Group for Sarcopenia: 2019 Consensus Update on Sarcopenia Diagnosis and Treatment. J. Am. Med. Dir. Assoc. 2020, 21, 300-307.e2. [CrossRef]

61. Cruz-Jentoft, A.J.; Sayer, A.A. Sarcopenia. Lancet 2019, 393, 2636-2646. [CrossRef]

62. Bischoff-Ferrari, H.A.; Orav, J.E.; Kanis, J.A.; Rizzoli, R.; Schlögl, M.; Staehelin, H.B.; Willett, W.C.; Dawson-Hughes, B. Comparative performance of current definitions of sarcopenia against the prospective incidence of falls among community-dwelling seniors age 65 and older. Osteoporos Int. 2015, 26, 2793-2802. [CrossRef] [PubMed]

63. Schaap, L.A.; van Schoor, N.M.; Lips, P.; Visser, M. Associations of sarcopenia definitions, and their components, with the incidence of recurrent falling and fractures: The longitudinal aging study amsterdam. J. Gerontol. A Biol. Sci. Med. Sci. 2018, 73, 1199-1204. [CrossRef] [PubMed]

64. Cawthon, P.M.; Lui, L.Y.; Taylor, B.C.; McCulloch, C.E.; Cauley, J.A.; Lapidus, J.; Orwoll, E.; Ensrud, K.E. Clinical definitions of sarcopenia and risk of hospitalization in community-dwelling older men: The osteoporotic fractures in men study. J. Gerontol. A Biol. Sci. Med. Sci. 2017, 72, 1383-1389. [CrossRef] [PubMed]

65. Nevitt, M.C.; Cummings, S.R. Type of fall and risk of hip and wrist fractures: The study of osteoporotic fractures. The Study of Osteoporotic Fractures Research Group. J. Am. Geriatr. Soc. 1993, 41, 1226-1234. [CrossRef] [PubMed]

66. Kulik, C. Components of a Comprehensive Fall-risk Assessment. In Special Supplement to American Nurse Today-Best Practices for Falls Reduction: A Practical Guide. 2011. Available online: http:/ / www.americannursetoday.com/Article.aspx?id=7634 \&fid=7364. (accessed on 19 May 2014). 
67. Avanecean, D.; Calliste, D.; Contreras, T.; Lim, Y.; Fitzpatrick, A. Effectiveness of patient-centered interventions on falls in the acute care setting compared to usual care: A systematic review. JBI Database Syst. Rev. Implement Rep. 2017, 15, 3006-3048. [CrossRef] [PubMed]

68. Toots, A.; Wiklund, R.; Littbrand, H.; Nordin, E.; Nordstrom, P.; Lundin-Olsson, L.; Gustafson, Y.; Rosendahl, E. The effects of exercise on falls in older people with dementia living in nursing homes: A randomized controlled trial. J. Am. Med. Dir. Assoc. 2019, 20, 835-842.e1. [CrossRef]

69. Peek, K.; Bryant, J.; Carey, M.; Dodd, N.; Freund, M.; Lawson, S.; Meyer, C. Reducing falls among people living with dementia: A systematic review. Dementia 2020, 19, 1621-1640. [CrossRef]

70. Livingston, G.; Huntley, J.; Sommerlad, A.; Ames, D.; Ballard, C.; Banerjee, S.; Brayne, C.; Burns, A.; Cohen-Mansfield, J.; Cooper, C.; et al. Dementia prevention, intervention, and care: 2020 report of the Lancet Commission. Lancet 2020, 396, 413-446. [CrossRef]

71. Iaboni, A.; Flint, A.J. The complex interplay of depression and falls in older adults: A clinical review. Am. J. Geriatr. Psychiatry 2013, 21, 484-492. [CrossRef]

72. Daly, R.M.; Dalla Via, J.; Duckham, R.L.; Fraser, S.F.; Helge, E.W. Exercise for the prevention of osteoporosis in postmenopausal women: An evidence-based guide to the optimal prescription. Braz. J. Phys. Ther. 2019, 23, 170-180. [CrossRef]

73. Gia, T.N.; Sarker, V.K.; Tcarenko, I.; Rahmani, A.M.; Westerlund, T.; Liljeberg, P.; Tenhunen, H. Energy efficient wearable sensor node for IoT-based fall detection systems. Microprocess. Microsyst. 2018, 56, 34-46.

74. Xu, T.; Zhou, Y.; Zhu, J. New advances and challenges of fall detection systems: A survey. Appl. Sci. 2018, 8, 418. [CrossRef]

75. Malasinghe, L.P.; Ramzan, N.; Dahal, K. Remote patient monitoring: A comprehensive study. J. Ambient Intell. Humaniz. Comput. 2019, 10, 57-76. [CrossRef]

76. Peel, N.M. Epidemiology of falls in older age. Can. J. Aging 2011, 30, 7-19. [CrossRef] [PubMed]

77. WHO. WHO Global Report on Falls Prevention in Older Age. Available online: https://www.who.int/ageing/publications/ Falls_prevention7March.pdf?ua=1 (accessed on 23 December 2020).

78. Wales, K.; Clemson, L.; Lannin, N.A.; Cameron, I.D.; Salked, G.; Gitlin, L.; Rubenstein, L.; Barras, S.; Mackenzie, L.; Davies, C. Occupational therapy discharge planning for older adults: A protocol for a randomised trial and economic evaluation. BMC Geriatr. 2012, 12, 34. [CrossRef] [PubMed]

79. Gale, C.R.; Westbury, L.D.; Cooper, C.; Dennison, E.M. Risk factors for incident falls in older men and women: The English longitudinal study of ageing. BMC Geriatr. 2018, 18, 117. [CrossRef] [PubMed]

80. Gale, C.R.; Cooper, C.; Aihie Sayer, A. Prevalence and risk factors for falls in older men and women: The English Longitudinal Study of Ageing. Age Ageing 2016, 45, 789-794. [CrossRef] [PubMed]

81. Stevens, J.A.; Ballesteros, M.F.; Mack, K.A.; Rudd, R.A.; DeCaro, E.; Adler, G. Gender differences in seeking care for falls in the aged Medicare population. Am. J. Prev. Med. 2012, 43, 59-62. [CrossRef] 